\title{
Shallow foundations for the support of vertical-wall bridge abutments: interaction between riprap and contraction scour
}

\author{
C. Huang, O. Suaznabar, Z. Xie, J. Shen, N. Tsou, C. Lin \\ Genex Systems-TFHRC, Mclean, Virginia, USA \\ K. Kerenyi \\ Federal Highway Administration-TFHRC, Mclean, Virginia, USA
}

\begin{abstract}
The database from flume experiments focused on the performance of riprap layouts based on field installations and FHWA HEC-23 design guidelines against clear-water abutment scour combined with Computational Fluid Dynamics (CFD) is used to investigate how flow fields at single span bridge openings, dominated by flow contraction, adjust in response to variations of bed roughness and cross-section geometry due to riprap installations. These adjustments increase bed shear stress magnitudes on the unprotected erodible bed leading to underestimated contraction scour depths therefore creating instability, and ultimately causing edge failure of the riprap. Based on the combined physical/numerical modeling approach an edge failureresistant riprap layout is proposed. Furthermore, the CFD approach provides an insight into shear stress magnitudes within a nonuniform bed roughness in the bridge opening, and a comprehensive flowdepth-riprap interaction model to define limits for "hydraulically narrow" bridge openings that might be prone to edge failure of the scour protecting riprap.
\end{abstract}

\section{INTRODUCTION}

Scour of bridge abutments is a common cause of bridge failure in the United States (Lee et al. 2013). Major damage occurs to bridge abutments during floods, mainly because of scour at the foundations, particularly when the abutments are built on shallow foundations and are located at or near the channel banks. Hydraulic Engineering Circular No. 23 (HEC-23), published by the U.S. Federal Highway Administration (Lagasse et al. 2009) provides procedures for designing abutment scour countermeasures that have been implemented in the United States. Much research has been conducted to determine the depth and location of the scour that develops around abutments, and numerous scour equations have been developed to predict this scour depth. These equations and procedures for predicting abutment scour depths can be found in HEC-18 (Arneson et al. 2012). In recent years a risk-based design approach has been recommended in HEC-18. The failure of the small bridges hydraulically designed for floods of lower recurring frequency may have less economic and social impact than the significant large bridges. It may not be necessary or cost effective to design the bridge foundation to withstand the effects of extraordinary large floods. In many cases, abutment foundations can be designed with shallower total scour depths than predicted by the equations when they are protected with rock riprap. This is the current design approach for vertical-wall abutments that are built on spread footings. The approach is to place the top of the foundation or footing below the depth of the sum of contraction scour and long-term degradation referenced to the thalweg of the main channel and to provide rock riprap to protect the abutment from local scour. Furthermore, these types of abutments are usually implemented for single span bridges. It is important to emphasize that about $80 \%$ of the over 600,000 bridges in the U.S. national inventory are single span bridges 21 to 27 meters in length (Adams et al. 2007). It has been recognized, therefore, that a sound countermeasure concept and better design guidelines need to be developed to protect bridge abutments that are built on shallow foundations from scour damage.

\section{ABUTMENT RIPRAP RESEARCH}

Riprap placed around the toe of an abutment protects the abutment foundation from scouring. The size of the rock enables them to resist the increased velocities and turbulence caused by the presence of the abutment in the flow. The riprap layer extent protects the underlying erodible bed sediment in the periphery of the abutment that otherwise might be exposed to the higher bed shear stresses induced by the highly turbulent flow. 
A number of researchers (Parola 1993), (Chiew 1995), (Lauchlan 1999), investigated riprap failure at bridge piers identifying four riprap failure mechanisms: shear failure, edge failure, winnowing failure and bed-form undermining. Similar failure mechanisms for riprap aprons placed around abutments have been identified based on flume experiments using single abutment models on fixed bed and erodible bed under both clear-water and live-bed conditions (Pagan-Ortiz 1991), (Melville et al. 2006). In addition the NCHRP report 587 (Barkdoll et al. 2007) provides new comprehensive research on riprap design for abutments and their approach embankments that was incorporated in HEC-23. Ettema et al. (2015) and $\mathrm{Ng}$ et al. (2015) made important findings on the embankment erosion of spill-through abutments during scour and showed that the interaction between geotechnical and hydraulic processes affect the scouring mechanism at the toe of the abutment.

\section{ABUTMENT RIPRAP AND CONTRACTION SCOUR INTERACTION}

As previously mentioned, a common design approach for vertical-wall abutments that are built on shallow foundations is to place the top of the foundation or footing at the same elevation as the sum of the predicted contraction scour and long-term degradation referenced to the thalweg of the main channel and to provide rock riprap to protect the abutment from local scour. Clear-water contraction scour results in a decrease of the elevation of the bed across the bridge opening, as the scour develops the bed shear stress $\tau_{\mathrm{o}}$ reduces to the critical shear stress $\tau_{\mathrm{c}}$ of the bed material in the section.
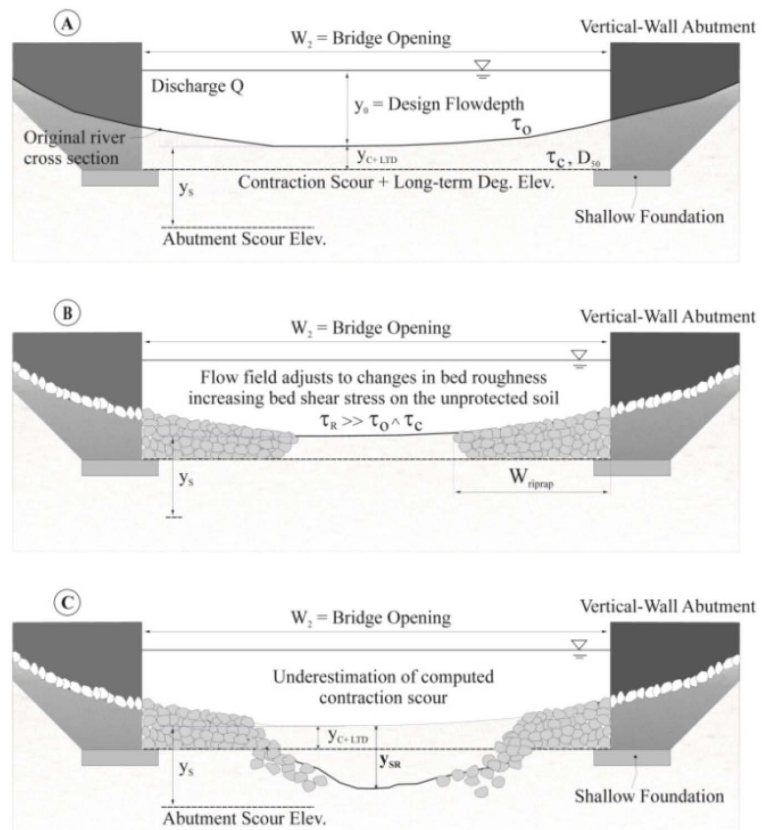

Figure 1 Sequence schema showing the impact of riprap apron on the predicted contraction scour.
In the bridge opening the contracted section is constrained by the abutment walls and the flow depth increases until equilibrium conditions are reached. The recommended clear-water contraction scour equation in HEC-18 is based on a development suggested by Laursen (Laursen 1963) where contraction scour depth $y_{C}$ is a function of the design discharge $Q$ through the bridge opening, the average existing depth in the opening $y_{0}$, the median diameter of bed material $D_{50}$, and the bottom width $W_{2}$ of the contracted section. Figure 1.A shows the parameters and cross-section geometry that are needed for computing $y_{\mathrm{C}}$ in the bridge opening. With this derivation it is assumed that flow goes from one uniform flow condition to another with deeper flowdepth and lower velocity. The abutment riprap layer placed as shown in Figure 1.B primarily protects the abutment foundation from local scour $y_{S}$, where for a good performance of the riprap layer a minimum apron thickness and extent $W_{\text {riprap }}$ is required that covers the range of the induced local scouring vortices on the erodible bed material near the abutments. In this arrangement the heterogeneous bed roughness in the bridge opening dominates the physics of the flow, initially manifested as strong secondary currents originating from the transition in surface roughness (riprap layer-erodible bed). An experimental investigation (T.U. Petersen et al. 2015) demonstrated how the generated flow turbulence laterally diffuses from the rough section over the riprap apron into the smoother bed sediment section. The adjustment of the flow through the bridge opening to the change in bed roughness leads to an increased bed shear stress $\tau_{\mathrm{R}}$ on the unprotected erodible soil leading to a deeper scour depth $y_{S R}$ Figure 1.C creating instability, and ultimately causing edge failure of the riprap.

To address these points and to provide a more complete picture of the flow field and local bed shear stresses on the heterogeneous bed roughness in the bridge opening, a series of physical experiments and numerical simulations were conducted.

\section{PHASE I: PHYSICAL MODELING}

\subsection{Model Layout and Experimental Equipment}

The experiments were conducted in a $1.83 \mathrm{~m}$ wide, $0.55 \mathrm{~m}$ deep and $21.35 \mathrm{~m}$ long with transparent glass side walls tilting, and water recirculating flume at the TFHRCs J. Sterling Jones Hydraulics Research Laboratory in Mclean, Virginia, US. 


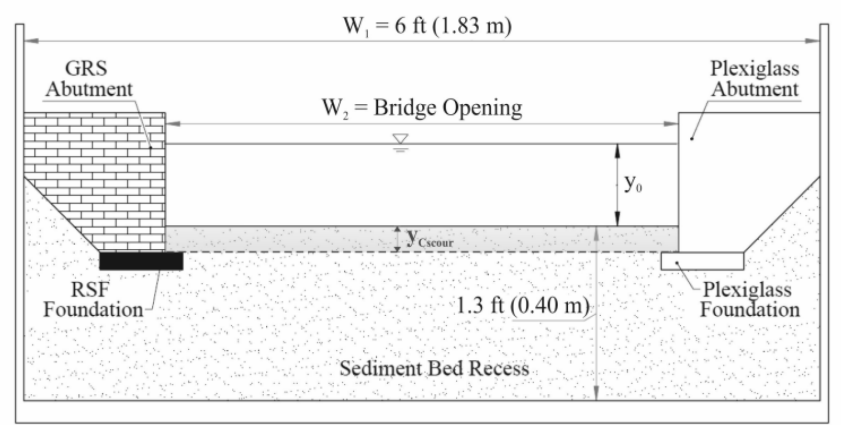

Figure 2 Cross-section view of the model layout used with different riprap installations

The flume is instrumented with an automated threeaxis positioning system, with traversing capability for the entire length width, and height of $1 \mathrm{~mm}$. This carriage can position probes at any location within the test section to make point measurements for flow velocities using an Acoustic Doppler Velocimetry (ADV) and bed bathymetry using a laser distance sensor. A $0.15 \mathrm{~m}$ layer of uniform sediment $D_{50}=1$ $\mathrm{mm}$ is evenly spread along the full length of the test section $(5.3 \mathrm{~m}$ long by $1.83 \mathrm{~m}$ wide). The sediment recess where the bridge opening with vertical-wall abutment models are placed is deep enough to model local scour to a maximum depth of $0.4 \mathrm{~m}$.

Motivation for the laboratory experiments was to study the impact of several riprap installations on the computed theoretical contraction scour depth for a small scale model of a single-span bridge opening. For this investigation HEC-18 Laursen's clear-water contraction scour equation was applied. Figure 2 shows a cross-section view of the layout with principal dimensions and relevant hydraulic parameters. Two vertical-wall model abutments built on shallow foundations with the same length are placed in the $0.4 \mathrm{~m}$ deep sediment bed recess making a contraction ratio of $W_{1} / W_{2}$, where $W_{1}$ is the channel width $1.83 \mathrm{~m}$ and $W_{2}=$ bridge opening width. The abutment width is scaled down to accommodate a road width for two lanes plus shoulders, based on U.S. standards. Froude similarity is applied to set the approach flow conditions, at the same time clear-water scour conditions on uniform bed sediment with a grain size median diameter of $D_{50}=1 \mathrm{~mm}$ are achieved.

\subsection{Riprap Layouts and Experimental Procedure}

Based on $W_{1} / W_{2}$ and given approach flow conditions the contraction scour is computed and the top of the shallow foundations are placed at the same elevation. Riprap on geotextile filter is then placed around both abutment models and tested against maximum equilibrium scour with a running time for each test of 24 hours. Using the laser distance sensor a digital bed bathymetry map is obtained to assess the scour depth $y_{S R}$ and compare it with the computed contrac- tion scour $y_{C}$. For the first set of experiments the riprap layouts are installed according to HEC-23 design guidelines e.g. D.G.14 and field installations. Complementary tests are conducted varying the layout and extent of the riprap apron. From the results and failure mechanisms observed a second set of experiments were conducted that includes a new proposed buried riprap layout for the same flow conditions and contraction ratio. Results and performance are compared in terms of $y_{S R}$ and edge failure of the riprap. Supplementary tests with the new proposed riprap layout are conducted for a new $W_{l} / W_{2}$ and approach flow conditions, giving a new contraction scour elevation. Figure 3 shows a cross-section layout of one of the riprap installations tested based on HEC-23 D.G. 14 for abutment riprap and two photos of this experiment, the first one A) as-built riprap installation and B) the experiment after a 24 hours running time at equilibrium scour showing edge failure of the riprap. In addition to comparing the predicted $y_{C}$ with the measured $y_{S R}$ at equilibrium, the riprap failure mode is assessed and the erosion process is described. The important findings from the experiments were that while riprap installations with a short apron extent $W_{\text {Riprap }}$ experienced edge failure related to a combination of local and contraction scour, riprap layouts with a large apron extent, e.g. $W_{\text {Riprap }}=2 y_{0}$ (example shown in Figure 3), experienced edge failure that results from the adjustment of the flow through the bridge opening to the change in bed roughness that leads to an increased bed shear stress on the unprotected erodible bed.
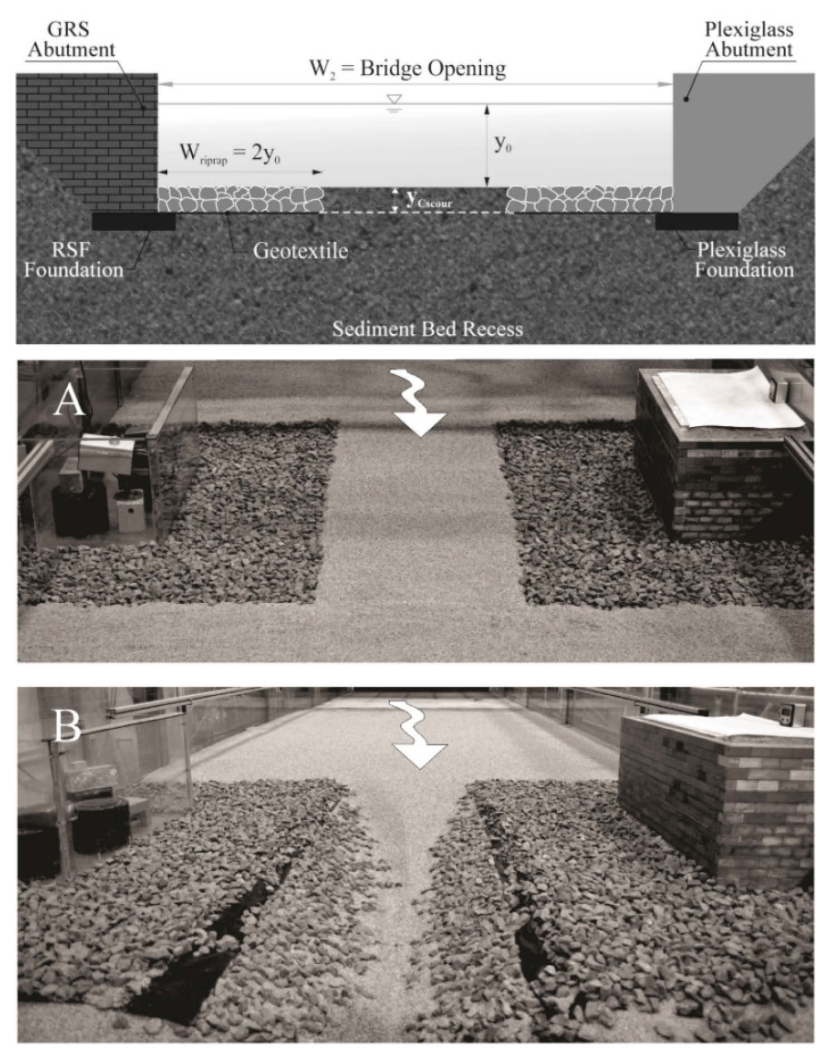

Figure 3 Cross-section view of HEC-23 D.G.14 Riprap installed in the test section: A) As-built. B) At equilibrium scour. 


\section{PHASE II: THEORETICAL ANALYSIS AND NUMERICAL MODELING APPROACH}

\subsection{Concept of Hydraulically Narrow Bridge Openings}

Based on the findings from the physical experiments it was identified that riprap aprons have an impact on the unprotected erodible soil and therefore on the computed contraction scour depth that does not include the riprap for its computation. This impact would apparently be more significant when the bridge opening is narrow. The purpose of this chapter is to derive a theoretical model in order quantify the impact of riprap on the erosion of the unprotected soil and contraction scour depth in the bridge opening. Figure 4 shows the plan view of a simplified bridge opening and relevant hydraulic parameters for this derivation, including the design upstream velocity $V_{1}$, velocity in abutment opening $V_{2}$, riverbed bottom width upstream $W_{1}$, bridge opening $W_{2}$, design flow depth upstream $y_{1}$, original flow depth in the opening $y_{0}$ (before scouring), abutment length $l_{1}$, and abutment width $l_{2}$.

For this model bed shear stress on the erodible river bed is chosen to quantify the impact of the riprap on the unprotected erodible bed. Figure 5 shows the comparison of the bed shear stress distributions from the results of two numerical models with identical geometry and hydraulic conditions, i.e., $W_{1}, W_{2}, V_{1}, y_{1}, l_{1}, l_{2}$, etc. $\tau_{\mathrm{o}}$ is the average bed shear stress on the erodible river bed for the model without riprap countermeasure, and $\tau_{\mathrm{R}}$ is the average bed shear stress on the erodible river bed for the model with riprap. For a better comparison, same river bed area of these two models is selected to calculate the average shear stress. In this case, apparently $\tau_{R}$ has a greater value than $\tau_{\mathrm{o}}$, i.e., the color of contour in the dash box of Figure $5 b$ is darker than that of Figure $5 \mathrm{a}$, which supports the existence of adverse effects induced by riprap as mentioned in Section 3.

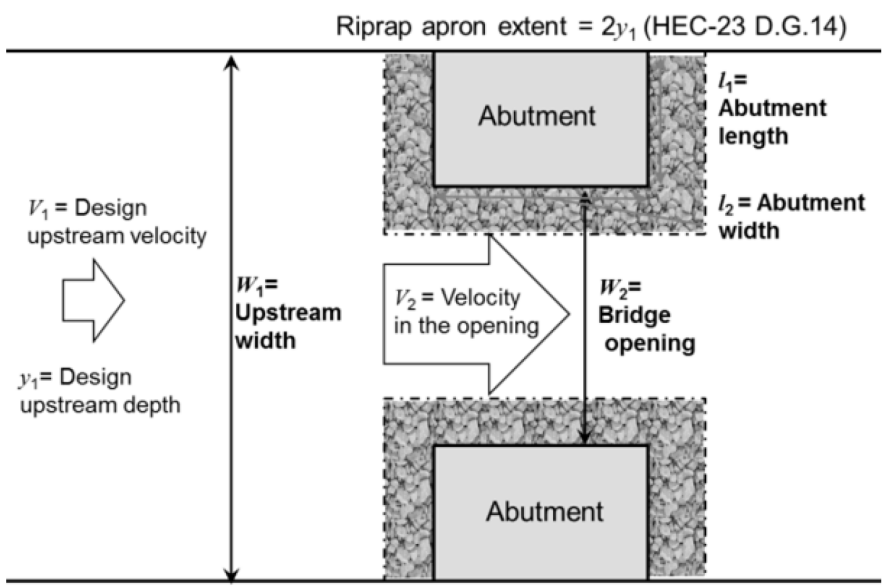

Figure 4. Plan view of a typical river channel and relevant hydraulic parameters.

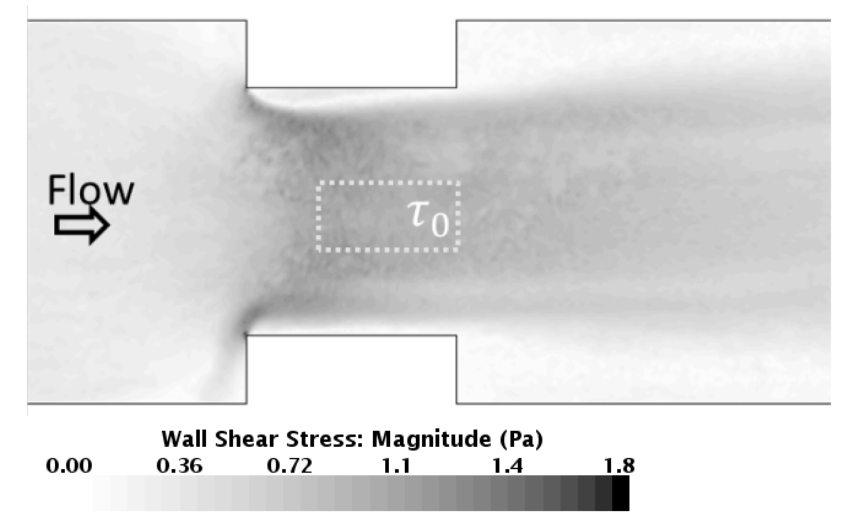

(a) Model without riprap countermeasure

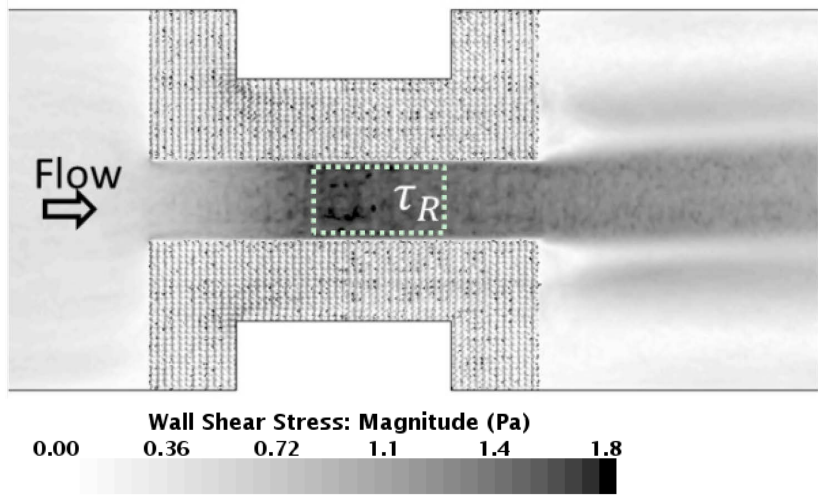

(b) Model with riprap countermeasure

Figure 5. Comparison on the bed shear stress distribution of numerical models without and with riprap countermeasure.

The bed shear ratio $\tau_{R} / \tau_{\mathrm{o}}$ will be used as an index to evaluate the influence induced by riprap installation. If we assume the upstream flow velocity $V_{1}$ and depth $y_{1}$ remain constant, and then artificially move the two abutments apart from each other, the impact from riprap is supposed to reduce with the increasing $\mathrm{W}_{2}$ because the riprap occupies less portion of the cross sectional submerged area of bridge opening.

Figure 6 shows a conceptual relationship between shear ratio $\tau_{\mathrm{R}} / \tau_{\mathrm{o}}$ and the opening-to-depth ratio $W_{2} / y_{0}$. Ideally, when riprap provides no influence on the flow condition, e.g., the opening is infinitely wide, the shear ratio $\tau_{\mathrm{R}} / \tau_{\mathrm{o}}$ will drop to 1.0 . In reality, due to the limited width of opening the $W_{2} / y_{0}, \tau_{\mathrm{R}} / \tau_{\mathrm{o}}$ will mostly be larger than 1 . Riprap will exhibit negligible impact on flow conditions and contraction scour depths when $W_{2} / y_{0}$ is increased to a relative large number. As shown in Figure 6, the hydraulically narrow opening is defined when $\tau_{R} / \tau_{o}$ is reduced to a value close to 1 . Hydraulically narrow openings need to be carefully dealt with to avoid possible riprap edge failure. For those openings with larger $W_{2} / y_{0}$, the installation of riprap has less impact resulting in the applicability of D.G. 14 in HEC-23. Note that when $W_{2} / y_{0}$ is less than 4 , the riprap apron extents from two abutments automatically form a full width protection because each riprap apron covers at least $2 y_{0}$ of the river bed. 


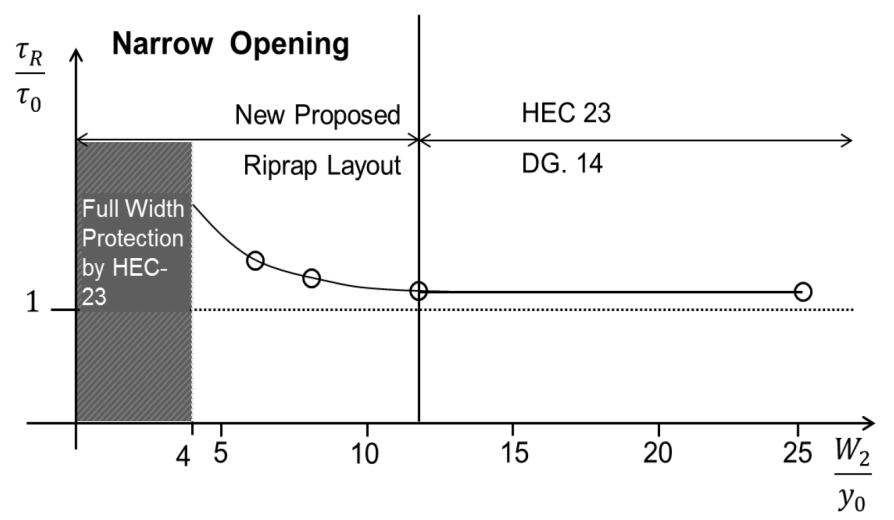

Figure 6. Conceptual definition of a hydraulically narrow opening that needs full width protection with buried riprap.

\subsection{Theoretical Model Formulation}

In open channel flow, the dimensionless analysis is used to better understand the dependent variables related to the definition of hydraulically narrow opening. The variables in open channel flow with riprap around the compound abutment will be $V_{1}, V_{2}, l_{1}, l_{2}$, $W_{1}, W_{2}, y_{1}, y_{0}$, the flow density $\rho$, gravity $g$, riprap size $D_{50}, \tau_{\mathrm{R}}$ or $\tau_{\mathrm{o}}$, viscosity $\mu$, and flow depth in the opening after scour $y_{2}$. The dimensionless analysis equation for the ratio of shear stress with riprap to the case without riprap can be written as,

$\frac{\tau_{R}}{\tau_{0}}=f\left(F r, \frac{l_{1}}{y_{0}}, \frac{W_{2}}{y_{0}}\right)$

Further, we assume the constant abutment dimensions for simplifying the modelling, thus, the equation above become the following formation,

$\frac{\tau_{R}}{\tau_{0}}=\varnothing\left(F r, \frac{W_{2}}{y_{0}}\right)$

Ideally, when $\tau_{R}>\tau_{\mathrm{o}}$, we identify the flow condition as a hydraulically narrow opening condition. The specific functional formulation need to be determined by continuity equation and energy equation. We apply the continuity equation and energy equation on a setup with riprap protection around abutment to the control volume as shown in Figure 7 between two cross sections at the open channel upstream and contraction, respectively

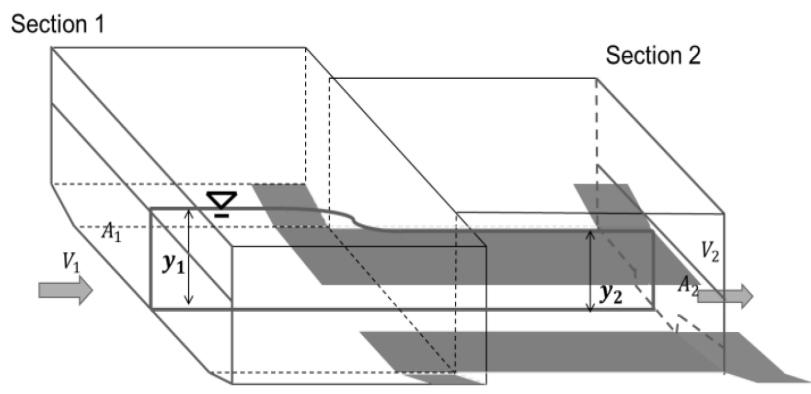

Figure 7. Control volume of an open channel with contracted sections.
Continuity equation can be written as

$V_{1} A_{1}=V_{2} A_{2}$

Energy equation for the model with riprap is

$z_{1}+y_{1}+\alpha_{1} \frac{V_{1}^{2}}{2 g}=z_{2}+y_{2}+\alpha_{2} \frac{V_{2}^{2}}{2 g}+h_{w}$

where $A_{1}$ and $A_{2}$ are the cross sectional area of upstream and opening, $\alpha_{1}$ and $\alpha_{2}$ are energy correction factors which equal to 1.0 for the gradual flow condition as we assume, $z_{1}$ and $z_{2}$ are the reference levels of two sections, and $h_{w}$ is the head loss between two cross sections which can be defined as $C_{c} \frac{V_{2}^{2}}{2 g}$.

Two assumptions have to be made to obtain the average bed shear stress in the contraction area, 1) the flow in the contracted section is gradual flow, and 2) the front faces of abutment are smooth. These assumptions accompanied with the momentum equation and Manning's $\mathrm{n}$ formula result in the derivation of average bed shear for the case with riprap in the opening as follows,

$\tau_{R}=\gamma\left(\frac{W_{2}^{\frac{1}{7}}}{A_{2}}\right)^{\frac{7}{3}}(Q n)^{2}$

where $n$ is composite Manning's roughness coefficient which can be calculated by utilizing the Horton-Einstein equation (Horton 1933, Einstein 1934),

$n=\left(\frac{p_{1} n_{r}^{1.5}+p_{2} n_{b}^{1.5}}{p}\right)^{\frac{2}{3}}$

where $n_{r}$ and $n_{b}$ are the roughness coefficient for riprap and erodible river bed as shown in Figure 8a and $8 \mathrm{~b}$, respectively. $p_{1}, p_{2}$ and $p$ are the bottom width for riprap, erodible river bed and entire channel, respectively. $n_{r}$ and $n_{b}$ can be calculated by Strickler's equation which relates roughness coefficient to the size of bed material (Strickler 1923).

In the contraction area, the flow condition in the opening with cross section as shown in Figure $8 \mathrm{a}$ is equivalent to the one with uniform roughness and shear stress in Figure 8b. $y_{e}$ is the equivalent flow depth in the opening and $\Delta \mathrm{Z}$ is the difference of reference levels. 


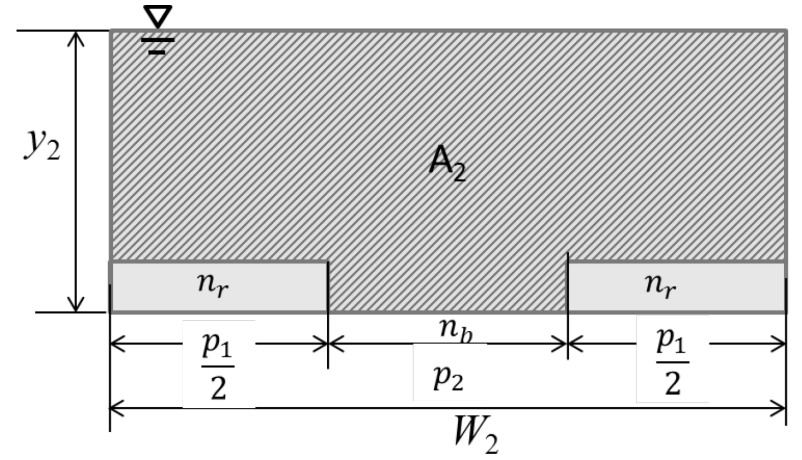

(a) Cross section with non-uniform roughness and bed shear

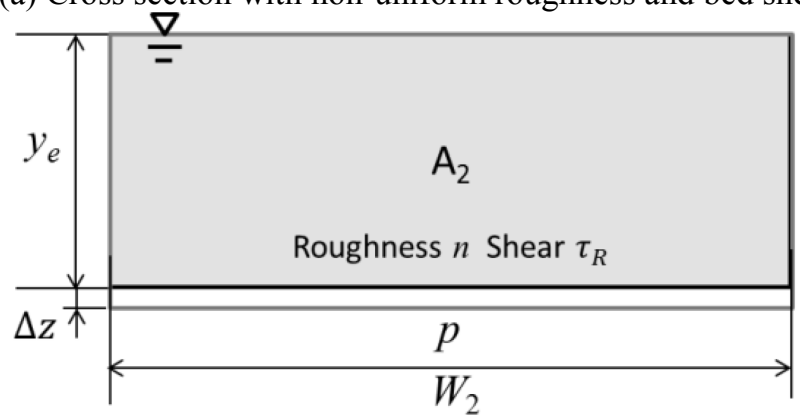

(b) Cross section with uniform roughness and bed shear

Figure 8. Two equivalent cross sections in the opening.

Based on the equations above, the specific formation for Equation 2 is derived as

$\frac{\tau_{R}}{\tau_{0}}=\left[\frac{4\left(\frac{n_{r}}{n_{b}}\right)^{1.5}+\left(\frac{w_{2}}{y_{0}}-4\right)}{\frac{w_{2}}{y_{0}}}\right]^{\varepsilon}\left(\frac{1+\alpha F r^{2}}{1+\beta F r^{2}-\frac{\Delta Z}{y_{1}}}\right)^{\frac{7}{3}}$

where $F r$ is Froude number and $\varepsilon$ is a function related to the ratio of roughness of riprap to that of erodible bed material, i.e., $n_{r} / n_{b}$, which will be determined from the analysis of the results from CFD simulation in the following section. Two parameters $\alpha$ and $\beta$ are

$\alpha=\left[1-\left(1+C_{c 0}\right) \frac{A_{1}^{2}}{A_{0}^{2}}\right]$

$\beta=\left[1-\left(1+\mathrm{C}_{\mathrm{ce}}\right) \frac{\mathrm{A}_{1}^{2}}{\mathrm{~A}_{2}^{2}}\right]$

where $C_{c 0}$ and $C_{c e}$ are the head loss coefficient of model without riprap and model with riprap, respectively.

\subsection{CFD Modeling Approach}

To determine the function $\varepsilon$ in Equation 7, two types of numerical models are developed to obtain the bed shear stress $\tau_{\mathrm{R}}$ and $\tau_{\mathrm{o}}$. One is the model without any countermeasure while the other is the model with riprap installed as recommended in HEC-23 D.G. 14. A well-benchmarked commercial Computational Fluid Dynamics (CFD) software STAR-CCM+ is used to simulate the hydraulic conditions in those models. The two types of CFD computational model domains representing open channels with contracted sections are shown in Figure 9.

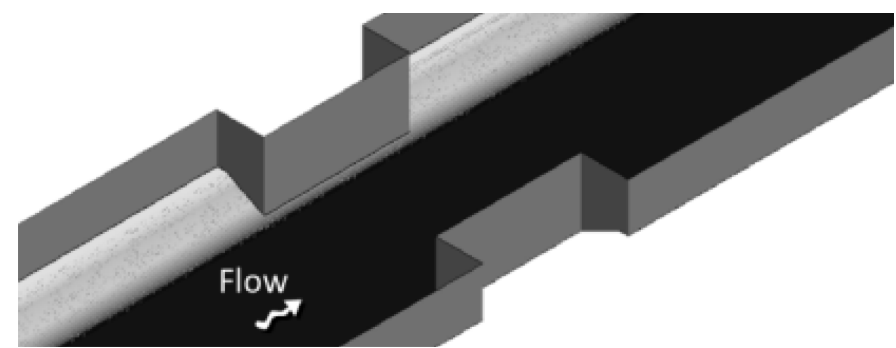

(a) Model without countermeasure

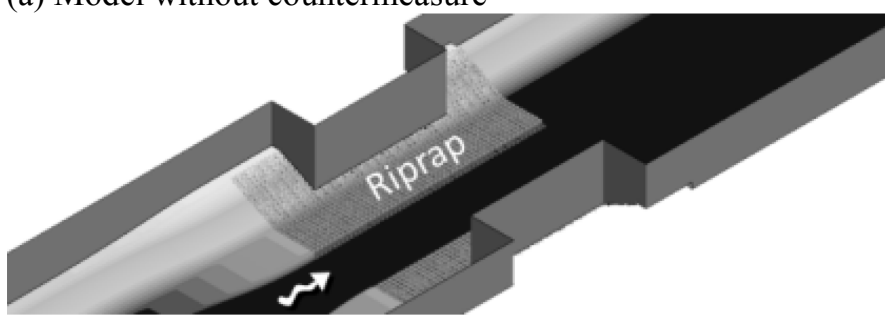

(b) Model with riprap installation

Figure 9. Diagram of CFD models.

\subsection{CFD Test Matrix}

To study the interaction between bed shear stress and riprap for bridge openings of different width, and also to investigate the definition of hydraulically narrow opening by validating the curve shown in Figure 6, a series of bridge opening models with different $\mathrm{W}_{2}$ and different riprap sizes have been modeled in CFD as shown in Table 1.

Table 1. CFD Test Matrix.

\begin{tabular}{llll}
\hline & Group \#1 & Group \#2 & Group \#3 \\
\cline { 2 - 4 } $\boldsymbol{W}_{2} / \boldsymbol{y}_{\mathbf{0}}$ & $V_{2}=0.6 \mathrm{~m} / \mathrm{s}$ & $V_{2}=0.75 \mathrm{~m} / \mathrm{s}$ & $V_{2}=0.9 \mathrm{~m} / \mathrm{s}$ \\
\cline { 2 - 4 } & $\begin{array}{l}\text { Riprap } D_{50}= \\
23 \mathrm{~mm}\end{array}$ & $\begin{array}{l}\text { Riprap } D_{50}= \\
35 \mathrm{~mm}\end{array}$ & $\begin{array}{l}\text { Riprap } D_{50}= \\
52.5 \mathrm{~mm}\end{array}$ \\
\hline 6.2 & Case 1 & Case 6 & Case 11 \\
8 & Case 2 & Case 7 & Case 12 \\
10 & Case 3 & Case 8 & Case 13 \\
12 & Case 4 & Case 9 & Case 14 \\
16 & Case 5 & Case 10 & Case 15 \\
\hline
\end{tabular}

In the test matrix, to determine the ratio of $\tau_{R} / \tau_{\mathrm{o}}$, each case consists of two CFD models as mentioned in Section 6.1. A total of 15 cases (30 models) are established which can be divided into three groups. Each group consists of five cases for bridge openings with $W_{2} / y_{0}$ range from 6.2 to 16 . Different groups have different riprap size $D_{50}$ and velocity in the opening $V_{2}$. The riprap size is determined by the sizing equation in HEC-23 as follows

$\frac{D_{50}}{y_{0}}=\frac{K}{\left(S_{S}-1\right)} F r^{2}$ 
where $S_{s}$ is the specific gravity of rock riprap and $K$ is a coefficient with a value of 0.89 for spill-through abutments and 1.02 for vertical-wall abutments.

Note that all numerical models are built with experimental scale. In particular, case 1 represents the physical experiments performed in the J. Sterling Jones Research Hydraulics Laboratory at the TurnerFairbank Highway Research Center as mentioned in Section 4.

\subsection{CFD Results}

For illustrative purposes, the velocity distributions of the central cross sections for Case 11 and 15 in Group \#3 are shown in Figure 10.

Figure 10 indicates that the bed shear stress of models without riprap (left plot in Figure10a and Figure 10b) exhibit very similar distributions for different values of $W_{2} / y_{0}$. The average bed shear stress in these trials is around $1.3 \mathrm{~Pa}$. On the contrary, the average bed shear stress with riprap drops dramatically, from $3.3 \mathrm{~Pa}$ for the Case 11 (the narrowest case, Fig. 10a) to $1.3 \mathrm{~Pa}$ for the Case 15 (the widest case, Fig. 10b).

Comparing the two plots in Figure 10b, the bed shear stress distribution for models with and without riprap are almost the same. This trend provides solid support for the concept mentioned in Section 5.1, i.e., the bed shear stress ratio $\tau_{\mathrm{R}} / \tau_{\mathrm{o}}$ will decrease with the increasing opening-to-depth ratio $W_{2} / y_{0}$.

Table 2 shows the summary of results for the 15 cases. Comparing the shear ratio between different groups, it can be seen that the shear ratio increases with the riprap size. For example, the shear ratios for three cases of same $W_{2} / y_{0}=6.2$ increase from 1.27 for Case 1, to 1.51 for Case 6, to 2.40 for Case 11 . The difference gradually reduces with increasing opening-to-width ratio, which indicates that the riprap size has significant impact on narrower openings. The bed shear ratio almost doubled from Case 1 to Case 11 where there is a lower opening-to-width ratio, but it is only $10 \%$ higher comparing Case 5 to Case 15 where the ratio is much higher. This phenomenon is mainly attributed to two factors: 1) the near-bed secondary turbulence is increased due to larger surface roughness coefficient of larger riprap, and 2) riprap of larger size occupies more cross sectional area in the opening assuming the contraction depth is equal to two times $D_{50}$ (two layers of riprap).

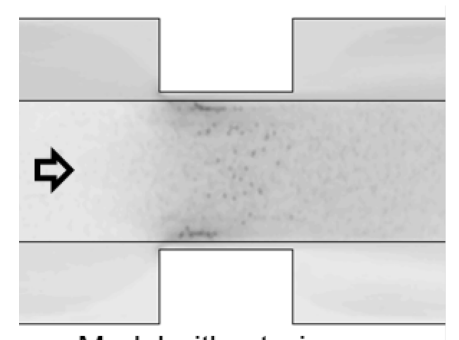

Model without riprap

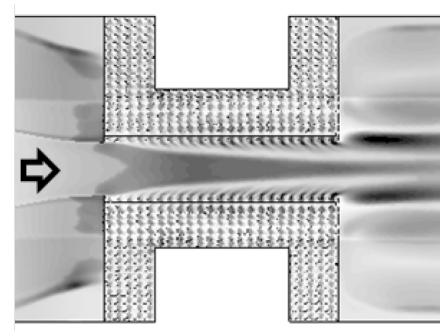

Model with riprap (a) Case 11

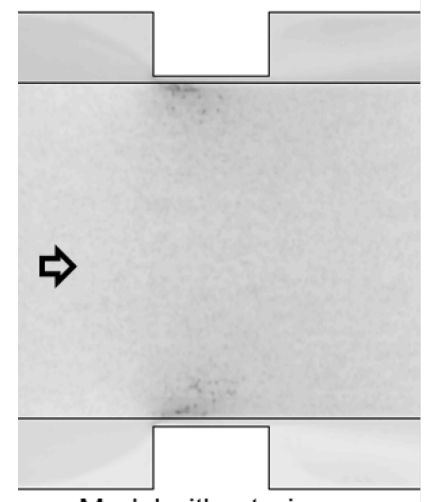

Model without riprap

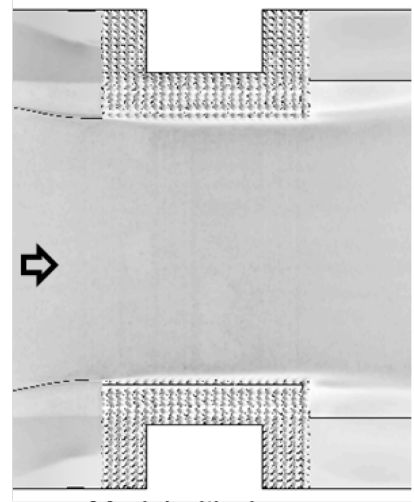

Model with riprap

Wall Shear Stress: Magnitude (Pa)

$\begin{array}{lllll}0.0 & 0.70 & 1.4 & 2.1 & 2.8\end{array}$

(b) Case 15

Figure 10. Results of bed shear distribution.

Table 2. Test Results from CFD Simulation.

\begin{tabular}{|c|c|c|c|c|c|c|}
\hline \multirow{2}{*}{ Group } & \multirow{2}{*}{ Case } & \multirow{2}{*}{$W_{2} / y_{0}$} & \multirow{2}{*}{$F r$} & \multirow{2}{*}{$\frac{\tau_{0}}{\mathrm{~Pa}}$} & \multirow{2}{*}{$\begin{array}{l}\tau_{R} \\
\mathrm{~Pa}\end{array}$} & \multirow{2}{*}{$\frac{\tau_{R}}{\tau_{0}}$} \\
\hline & & & & & & \\
\hline \multirow{5}{*}{$\begin{array}{c}\# 1 \\
\left(D_{50}=\right. \\
23 \mathrm{~mm})\end{array}$} & 1 & 6.2 & 0.25 & 0.91 & 1.16 & 1.27 \\
\hline & 2 & 8 & 0.26 & 0.89 & 1.07 & 1.21 \\
\hline & 3 & 10 & 0.27 & 0.89 & 1.01 & 1.14 \\
\hline & 4 & 12 & 0.28 & 0.90 & 0.96 & 1.06 \\
\hline & 5 & 16 & 0.29 & 0.88 & 0.90 & 1.03 \\
\hline \multirow{5}{*}{$\begin{array}{c}\# 2 \\
\left(D_{50}=\right. \\
35 \mathrm{~mm})\end{array}$} & 6 & 6.2 & 0.25 & 1.16 & 1.76 & 1.51 \\
\hline & 7 & 8 & 0.26 & 1.08 & 1.44 & 1.34 \\
\hline & 8 & 10 & 0.27 & 1.03 & 1.24 & 1.21 \\
\hline & 9 & 12 & 0.28 & 0.98 & 1.16 & 1.18 \\
\hline & 10 & 16 & 0.29 & 0.92 & 1.04 & 1.13 \\
\hline \multirow{5}{*}{$\begin{array}{c}\# 3 \\
\left(D_{50}=\right. \\
52.5 \mathrm{~mm})\end{array}$} & 11 & 6.2 & 0.25 & 1.40 & 3.34 & 2.40 \\
\hline & 12 & 8 & 0.26 & 1.40 & 2.68 & 1.91 \\
\hline & 13 & 10 & 0.27 & 1.21 & 1.69 & 1.39 \\
\hline & 14 & 12 & 0.28 & 1.14 & 1.49 & 1.31 \\
\hline & 15 & 16 & 0.29 & 1.13 & 1.28 & 1.13 \\
\hline
\end{tabular}

The results in Table 2 provide an important and solid background for validating the interaction between flow, riprap and bed shear stress. As mentioned in Section 6.1, these data sets will be further utilized to determine the function $\varepsilon$ in Equation 7. A curve-fitting process is conducted based on Least 
Square Method (Legendre 1805) to determine the function $\varepsilon$.

Figure 11 shows the relationship between shear ratios and opening-to-depth ratios for all cases. The fitting curve based on Equation 7 for three groups are plotted against CFD results to verify its accuracy. The curve-fitting shows good agreement with the results from CFD modeling for all groups.

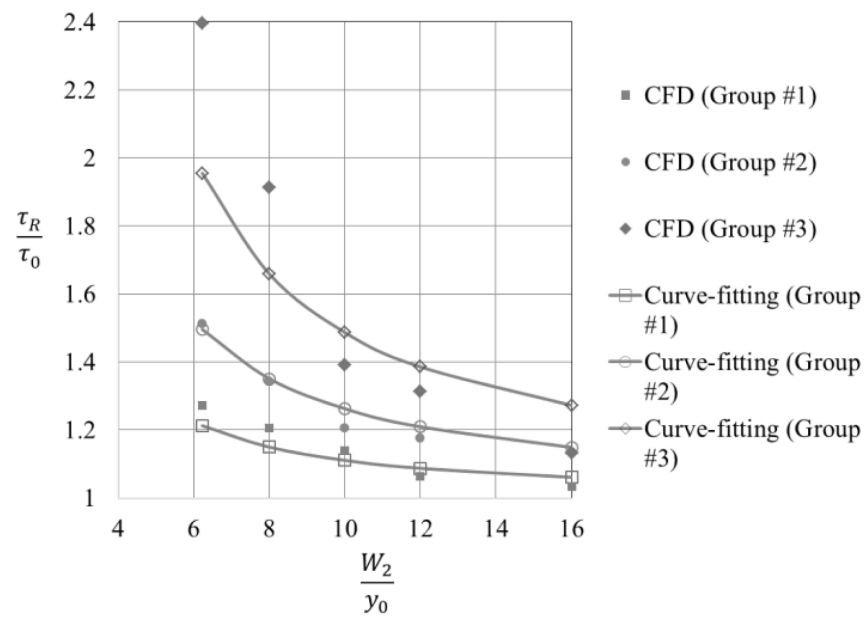

Figure 11. The relationship between bed shear ratios and opening-to-depth ratios for all CFD models

\section{DEFINITION OF HYDRAULICALLY NARROW BRIDGE OPENINGS}

Ideally, when the resulting bed shear ratio $\tau_{R} / \tau_{\mathrm{o}}$ is close to 1 , the bed shear stress induced by the flow on the erodible bed is not affected by the abutment riprap installation. The results presented in Table 2 do not show bed shear ratios that are equal to 1 but most of them are close to 1 with the minimum value for $\tau_{R} / \tau_{o}=1.03$. Furthermore, in figure 11 it is difficult to identify an apparent turning point either on the numerical results or on the fitting curve. A possible solution that can be applied for this analysis in order to identify the turning point in each curve comes from seismic design for bridges, the structural behavior (moment-curvature) of concrete columns is the key to establish reliable earthquake resistant systems. California Department of Transportation (Caltrans 2013) proposed that a realistic momentcurvature curve can be idealized with an elastic perfectly plastic response to estimate the plastic moment capacity of a member's cross section, as shown in Figure 12. Similarly, Intersection of this secant line and the ideal criteria of non-narrow opening $\tau_{\mathrm{R}} / \tau_{\mathrm{o}}=1.0$ is considered as the boundary of hydraulically narrow opening conditions. Figure 13 shows how the narrow opening is defined for the three groups in Table 2. It can be seen that the criterion to define narrow opening falls between 8 and 10 in terms of width-to-opening ratio, i.e., $W_{2} / y_{0}=8 \sim 10$.

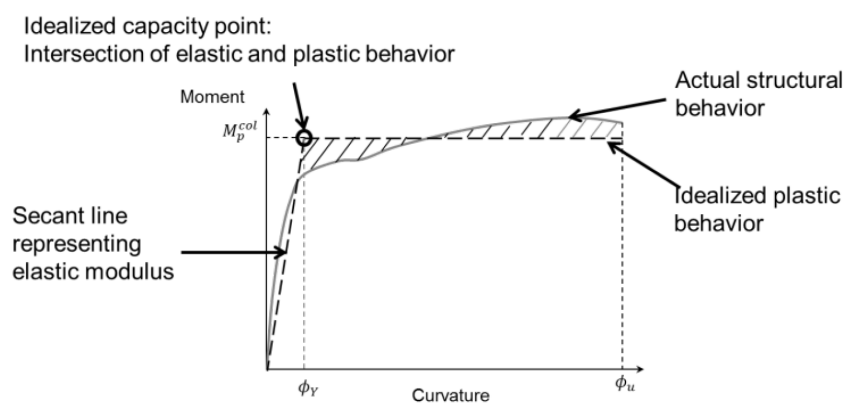

Figure 12. Idealized elastic perfectly plastic moment curvature for ductile concrete members (Caltrans 2013)

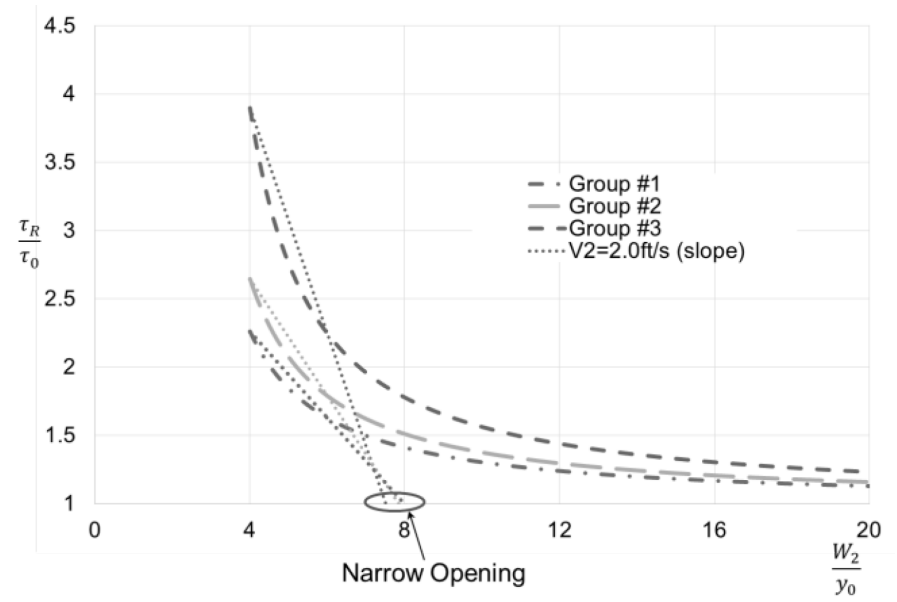

Figure 13. Definition of narrow opening from the CFD modeling cases.

\section{CONCLUSIONS}

A few conclusions can be drawn from the discussion above:

1) The excess bed shear on the unprotected erodible bed caused by the riprap decreases with the increasing bridge opening, which indicates that riprap layouts based on field installations and on current design guidelines have a greater impact on the potential increase of contraction scour for narrow single span bridge openings.

2) The bed shear ratios of larger riprap models are higher than those of smaller riprap models because of their increased roughness.

3) The interaction between flow, riprap layout and contraction scour depth suggests that the hydraulically narrow opening criterion can be defined as $W_{2} / y_{0}=8 \sim 10$.

\section{ACKNOWLEDGEMENTS}

The authors would like to thank the Argonne National Laboratory, for the use of the high performance computers at Argonne's Transportation Research And Analysis Computing Center (TRACC). 
$y_{C}-$ Contraction scour depth

$y_{S}-$ Local scour depth

$Q$ - Design discharge

$W_{\text {riprap }}$ - Apron extent of riprap

$y_{S R}$ - Increased scour depth due to riprap countermeasure

$V_{1}$ - Design upstream velocity

$V_{2}$ - Velocity in bridge openings

$W_{1}$ - Riverbed bottom width upstream

$W_{2}$ - Bridge opening

$y_{1}-$ Design flow depth upstream

$y_{0}$ - Original flow depth in the opening (before scouring)

$l_{1}$ - Abutment length

$l_{2}-$ Abutment width

$\tau_{\mathrm{o}}$ - Average bed shear stress on the erodible river bed for the model without riprap countermeasure

$\tau_{R}-$ Average bed shear stress on the erodible river bed for the model with riprap

$\rho-$ Flow density

$g$ - Gravity

$D_{50}-$ Riprap size

$\mu-$ Viscosity

$y_{2}$ - Flow depth in the opening after scour

$A_{1}$ - Cross sectional area upstream

$A_{2}$ - Cross sectional area of the opening

$p_{1}-$ Bottom width of riprap

$p_{2}-$ Bottom width of erodible river bed

$p$ - Bottom width of entire channel

$\alpha_{1}$ - Energy correction factors for models without riprap

$\alpha_{2}-$ Energy correction factors for models with riprap

$z_{1}$ - Reference levels of upstream section

$z_{2}$ - Reference levels of downstream section

$h_{w}-$ Head loss between two cross sections, $=\mathrm{C}_{\mathrm{c}} \frac{\mathrm{V}_{2}^{2}}{2 \mathrm{~g}}$

$n$-Composite Manning's roughness coefficient

$n_{r}$ - Roughness coefficient for riprap

$n_{b}$ - Roughness coefficient for erodible river bed

$y_{e}-$ Equivalent flow depth in the opening

$\Delta \mathrm{Z}$ - Difference of reference levels

$\mathrm{Fr}$ - Froude number

$\varepsilon-$ A function related to the ratio of roughness coef-

ficient of riprap to that of erodible bed material

$C_{c 0}$ - Head loss coefficient of model without riprap

$C_{c e}-$ Head loss coefficient of model with riprap

$S_{S}$ - Specific gravity of rock riprap

$K$ - Coefficient equals to 0.89 for a spill-through abutment and 1.02 for vertical wall abutment.
Adams, M., Schlatter, W. \& Stabile, T. 2007. Geosynthetic Reinforced Soil Integrated Abutments at the Bowman Road Bridge in Defiance County, Ohio. Geosynthetics in Reinforcement and Hydraulic Applications: 1-10.

Arneson, L.A., Zevenbergen, L.W., Lagasse, P.F. \& Clopper, P.E. 2012. Evaluating Scour at Bridges. Hydraulic Engineering Circular No.18. Washington D.C.: FHWA.

Barkdoll, B.D., Ettema, R., \& Melville, B.W. 2007. Countermeasures to Protect Bridge Abutments from Scour. NCHRP Report 587. Transportation Research Board. Washington D.C.: TRB

Caltrans. 2013. Seismic Design Criteria, Chapter 3: Capacities of Structure Components. California: Caltrans

Chiew, Y.M. 1995. Mechanics of Riprap Failure at Bridge Piers. Journal of Hydraulic Engineering. 121(9): 635-643.

Einstein, H.A. 1934. Der Hydraulische Oder ProfilRadius. Schweizerische Bauzeitung, Zurich, 103(8): 89-91.

Ettema, R., Ng, K., Chakradhar, R., Fuller, J., and Kempema, E. 2015. Failure of Spill-Through Bridge Abutments during Scour: Flume and Field Observations. Journal of Hydraulic Engineering. 141(5):06015001(1)-06015001(5)

Horton, R.E. 1933. Separate roughness coefficients for channel bottoms and sides. Engineering News-Record, 111(22): 652-653.

Lagasse, P.F., Clopper, P.E., Pagán-Ortiz, J.E., Zevenbergen, L.W., Arneson, L.A., Schall, J.D. \& Girard, L.G. 2009. Bridge Scour and Stream Instability Countermeasures. Hydraulic Engineering Circular No. 23. Washington D.C.: FHWA.

Lauchlan, C.S. 1999. Countermeasures for Pier Scour. Ph.D. thesis, The Univ. of Auckland, Auckland, New Zealand.

Laursen, E.M. 1963. An Analysis of Relief Bridge Scour. Journal of Hydraulic Division, ASCE, 89, No. HY3.

Lee, G.C., Mohan, S.B., Huang, C., \& Fard, B.N. 2013. A Study of U.S. Bridge Failures (1980-2012), Technical Report MCEER 13-0008, MCEER: Buffalo, NY.

Legendre, A.M. 1805. Nouvelles méthodes pour la détermination des orbites des comètes [New Methods for the Determination of the Orbits of Comets] (in French), Paris: F. Didot.

Melville, B., van Ballegooy, S., Coleman, S. \& Barkdoll, B. 2006. Scour Countermeasures for Wing-Wall Abutments. Journal of Hydraulic Engineering. 132(6): 563-574.

Ng, K.W., Chakradhar, R., Ettema, R. \& Kempena, E.W. 2015. Geotechnical Considerations in Hydraulic Modeling of Bridge Abutment Scour. Journal of Applied Water Engineering and Research. 3(2): 132-142

Pagan-Ortiz, J. E. 1991. Stability of Rock Riprap for Protection at the Toe of Abutments Located at the Floodplain. FHWARD-91-057. Washington D.C.: FHWA.

Parola, A.C. 1993. Stability of Riprap at Bridge Piers. Journal of Hydraulic Engineering. 119(10): 1080-1093.

Petersen, T., Sumer, B., Bøgelund, J., Yazici, A., Fredsøe, J. \& Meyer, K. 2015. Flow and Edge Scour in Current Adjacent to Stone Covers. Journal of Waterway, Port, Coastal, Ocean Engineering. 141(4): 04014044(1)-04014044(11).

Strickler, A. 1923. Mitteilungen des Eidgenossischen Amtes fuer Wasserwirtschaft 16, Bern, Switzerland. Translated as "Contributions to the question of a velocity formula and roughness data for streams, channels and closed pipelines." by T. Roesgan and W. R. Brownie, Translation T-10, W. M. Keck Lab of Hydraulics and Water Resources (1981), Calif. Inst. Tech., Pasadena, USA. 